\title{
Research on the Innovative Strategy of Experiential Marketing in Community Banks against the Background of Internet Finance
}

\author{
Xuehong Zhao \\ School of Management \\ Harbin Finance University \\ Harbin, China \\ 23212949@qq.com
}

\author{
Zhaoqi Liu* \\ School of Management \\ Harbin Finance University \\ Harbin, China \\ sunshoone@126.com
}

\begin{abstract}
The raise of the internet finance has a huge impact on the banking sector. Banks must change the management pattern and operation pattern; fully take the advantages of the internet to attract more customers. The customers experience is the most important factor that the bank should consider. Based on community banks as the research object, this paper discusses how to conduct experiential marketing against the background of the internet finance. Through the analysis of the current situation of the development of community banks and the characteristics of the experiential marketing, this paper puts forward the innovative strategy of experiential marketing in community banks in order to raise the overall service level.
\end{abstract}

Keywords-Internet finance; Community banks; Experiential marketing; Innovative strategy

\section{INTRODUCTION}

Internet-based finance is the integration of financial function and internet, which is based on cloud computing and big data with the advantages of information technology. It shows strong innovative and competitive to a certain extent, causes the creation of the financial industry, and it also puts forward the increasing of the higher requirements on banking development[1]. Commercial banks attempt to increase customers by establishing the banks in community. Community banks are given the financial mission of "the last kilometer", and they also become the important tools and means of commercial banks to take the initiative to grasp the strategic opportunity [2].

In order to achieve breakthrough and development, an urgent need for community banks is to carry out marketing innovation so as to create value, namely the value of a winwin situation with customers. At the same time, the development of marketing innovation of community banks cannot leave out the progress of information technology, for it provides supports and guarantee. Community banks need to make full use of the advantages of internet technology and information technology, select the direction and path of the development of marketing innovation to realize the perfect integration of information technology and business. Marketing

This Research was Supported by Youth Innovative Talents Training Project of Harbin Finance University in 2016 (E052016001), Harbin Finance University Important Subject in 2017 (E012017006) and the Basic Research Fee Project of Heilongjiang Provincial Universities in 2017(2017-KYYWF0083). innovation bases on the technology of information and internet needs to communicate constantly with customers, and this is in accordance with the concept of the internet finance that stresses the user supreme and the customers' experience is the king. Marketing innovation full play customers' creativity, achieve the customer value as the first target, see the customers as the important development resources of enterprise, let customers perceive the advantages for them which bring about by the creation and volunteer to participate.

\section{COMMUNITY BANKS AND EXPERIENTIAL MARKETING}

\section{A. The Development Status of Community Banks}

With the purpose of serving the regional life and business center, community banks are quick and convenient banking service places. They have smaller organizational structure, and the service objects are more for small and medium-sized enterprises and residents. Community banks are based on relational credit, with fast information transmission, high management and decision-making efficiency. The third plenary session of the 18th central committee of the communist party of China explicitly proposed to develop inclusive finance, which provided opportunities for the development of community banks as well as challenges. At present, the development of community banks in China mainly has the following characteristics:

\section{1) Weak in innovative ability}

Products and services are the key to the development of community banks, and they are the inevitable choice of improving customer experience and the increase of customer retention. Some of the community banks provides the community residents card and provide staggered time service and products according to the characteristics of the target customer. But overall, the distinction is small, and it lacks of integrated financial services solutions and innovation.

\section{2) Inaccurate positioning}

At present, most of the laws and regulations on community banks in China are drawn from the development ideas of community banks in Europe and the United States, and they have not highlighted the development advantages according to their own situation. Some community banks position 
themselves as a smaller version of the branches, provide services to community, pursuit the additional outlets and the purpose of scale expansion to construct them bigger and stronger. In fact, the true sense of community banks should design integrated and reasonable planning according to the geography, economic development level and consumption situation of the target customer, and their function should position as to provide the community customers with all-round financial services. Community clients include not only the community residents, but also industrial parks and business circles of enterprise users [3].

\section{3) Homogenization of services}

Because of single product variety, community banks' homogeneity is relatively serious, the design of products and services for residents in the community is less, and they also haven't considered the long-term sustainable development, fully excavated the different needs of different customers. They ignored the potential customer resource development and the subdivision depth for the existing customer resources is not enough.

\section{B. The Connotation and Characteristics of Experiential Marketing}

Experiential marketing is accompanied by experience economy. Experience economy, as the inevitable outcome of economic development, will occupy an increasingly important position. Under the condition of experiencing economy, the traditional marketing model faces the declining market share, and the innovative marketing mode is the inevitable choice for the survival and development of the enterprise. The birth of the internet has had a great impact on the traditional marketing mode, which has ushered in a new era of experiential marketing.

\section{1) The connotation of experiential marketing}

Experiential marketing is the application of experience building to the marketing of products and services, by a new planning and design of a product or service, experiential marketing attracts the customers' attention, exerts a direct impact on the customers' thought and feeling, fully meets the needs of consumers, gives consumers deep impression in the experience and good feelings. It is a marketing way to facilitate the purchase behavior [4].

\section{2) The characteristics of experiential marketing}

Firstly, diversification. Compared with the traditional way of marketing, experiential marketing pays more attention to the process of experience, it promotes the result by process, flexibly responses according to the characteristics of the environment, considers how to attract the attention of the customers in the process of experience by bringing good feeling to customers; Secondly, humanization. Experiential marketing focuses on customers' thoughts and feelings, really takes the customers as the center, obtains customers psychological identity, and the whole experience process meets customers' demand. The experience process design considers the perspective of the customers; Thirdly, interactivity. In the process of experiential marketing, enterprises guide customers to participate in it and cooperate and promote each other through communication. Compared with traditional marketing, experiential marketing pays more attention to the interaction with customers, and only an impressive experience for customers can be a meaningful experience [5].

\section{INNOVATIVE STRATEGY OF EXPERIENTIAL MARKETING}

Against the internet financial background, experience have the same status as the product and service. To attract customers rely only on the good product is far from enough. It becomes more and more important to build the community banks with innovate service experience, the strengthen effect of product display, and meticulously service experience. Schmidt defines the customers experience in different forms of aspects, including perception, emotion, thought, action, and association. In this paper, combining with the characteristics of community banks and the particularity of products, considering to bring the customers' psychological security in the process of experience. we will explore experiential marketing innovative strategy of community banks from six aspects, including sensory experience, emotional experience, thought experience, operation experience, associated experience strategy, security strategy.

\section{A. Sensory Experiential Strategy}

Sensory experience emphasizes comfort. The sense is the bridge between what the product expresses and what the user feels. The sensory experience is not isolated, it achieves the final effect through the cooperation and the contact of visual, auditory, touch, smell, taste and other sensory organs. Services of community banks are intangible, which needs to establish a multi-level comprehensive sensory experience through the tangible demonstration, such as from a decorating style, decoration items, bright degree, ambience. According to the different aesthetic habits of the target customers, the sensory experience meets customer demands and makes the customers to identify the products effectively in much homogeneous products, increases the added value of products and satisfies the customers' good experience.

People obtained about $80 \%$ information by visual, and the color is the first important factor of visual sensory stimulation factors. More attention should be paid to the brand color of banks, it should be clearly displayed and be unanimous with the overall brand image. For example, the brand color of Harbin bank is mainly yellow, considering the integrity and unity of the senses, the decorated style and the layout color be dominated by yellow. Comfortable voice can make people enjoyed, and too loud voice is noise. Community banks can play soothing background music, let the customers in the relaxed and happy environment for business, and the volume should control under 40 decibels, switch different music under special situation. Sense of touch is an important means of positioning, human can form tactile sense impression of the product and perception. Community banks should offer products or services through the tangible carrier, let people have different feelings, and they should emphasis the selection of the items material qualities on display. 


\section{B. Emotional Experiential Strategy}

Emotional experience emphasize friendly service. Emotional experiential marketing appeal points lie in the inner feelings and emotions. Stimulating the customers' feelings by words, actions and considerate care creates an emotional experience so as to create a " big housekeeper of community”.

\section{1) Pay attention to the detail care}

The attention of detail care can exceed customer satisfaction, so that it can enhance customer loyalty. By importing the real emotion, paying attention to the way of communication, impressing the customers with affection, making the experiential marketing more humane, community banks gain the trust and emotional identity of the customers to the enterprise. Community banks should be good at figuring out customer psychology and predicting customer needs. Also, community banks staff should improve their professional skills, master the operation process of each business, so that they can provide professional solutions when customers have questions about the business operation.

\section{2) Attentive service}

Community banks should make full use of fragmented time and fragmentation publicity materials. They also should offer considerate services when the customers come to the community banks so as to create marketing opportunities. The community banks should grasp the characteristics of their "community involvement" and develop the cooperation with mobile operators, social media, the third party and other internet upstream and downstream enterprise strategic. They should provide vigorously convenient life for residents, such as the collecting fees of the electricity, water, gas, heating, phone and other business which fully embody care and respect to customers. These service make customers feel respect and sense of belonging and reflect the status of consumer.

\section{3) Create warm atmosphere}

Experience scenes and atmosphere affect whether customers make a buying decision. Good experience scenes and atmosphere will attract customers, build good emotional atmosphere, make customers get some emotional experience, these can create memorable memories. In the meaningful festivals, community banks should have their own theme, for example, in Arbor Day, community banks can choose "plant protection" as the theme, in the Mid-Autumn festival, choose "reunion" as the theme. The appropriate theme express the corporate culture and brand connation and will give customers an unforgettable memory.

\section{Thinking Experiential Strategy}

The thinking experience emphasizes creation. It arouses customers' curiosity and interests in products or services in novel ways. The thinking experience is to encourage consumers to think creatively and to re-evaluate products and services and to understand products or services more deeply.

With the help of advanced IT technology and internet technology, community banks launched self-service counter, remote video attachment, interactive experience wall, these stimulate consumers to think, and then they will interested in inquiring what they are and what to do, these make customers imagine and think creatively. At last, these can improve the customer experience better.

By providing a new experience of thinking, community banks help consumers gain new knowledge in the experience, so that the consumers will be interested in their services, and this will arouse the curiosity of consumers. At the same time, community banks should pay attention to the introduction of financial knowledge to community residents, so that they can experience with their thoughts, and this help customers feel deeply the convenience and speed brought by financial services.

Community banks are good at stimulating consumer's thinking by a variety of support experience themes, such as the financial knowledge quiz activities, they inspiring the customers' interests in finance consumption and rich customers' financial knowledge, improving continuously customers enjoy the popularity of the modern financial services.

\section{Action Experiential strategy}

Action experiential strategy emphasizes participation. Action experience affects the customers' physical experience, lifestyle. Changes in customer lifestyle are stimulated or spontaneous, and community banks can exhibition diversify lifestyles through customers' participation, and thereby enriching consumers' lives.

Community banks should provide a complete set of experiential participation process for customers to participate and deepen the customers' impression of the community banks. They also can stimulate the customers to change lifestyles by financial professionals or opinion leaders, so that they will act up and have the purchase behaviors. Community banks should invite finance experts to give lectures, and invite the community residents opinion leader to participate the theme activities; they can organize experiential marketing activities that combined with photography, painting, music, series of activities such as "electronic exclusive hand-painted community card". Customers can not only learn some knowledge of painting but also can try using electronic technology to draw their favorite pattern in the bank cards of community banks, and this experience will bring customers the unforgettable memories.

From a foreign bank management practice, when customers acquire information and buy financial products, they are more likely to choose the physical network. Physical network business absolute amount are still rising. Community banks should make full use of their regional advantages, build a complete community business chain, really set up "online electronic-commerce add offline community banks” integrated platform, promote and introduce bank products, set up community joint name card, and corporate with the surrounding food, beauty, teaching, fitness, shops, create a community internet banking scene, build community financial services supermarket, so as to satisfy customer' all-round demands. 


\section{E. Correlative Experiential Marketing Strategy}

Correlative experiential marketing emphasizes attractiveness. It doesn't look the product or service separately. It puts all the associated information as a whole, assembles the consumer and community banks closely, enhance the value of community banks in the hearts of the community residents. community banks should build the core competitiveness which satisfy the needs of community customers, dig deeply the community clients' most pressing financial demand, innovate community bank brand connotation, and thus form a specific groups with common interests, so that the consumer gets experience of community relationships, including emotional experience from group interaction, thinking experience, information exchange, sense of value identity. community banks can really realize its development value by convenient, differentiation, personalized service. community banks also should build the brand effect, pass the brand effect to the customers through various channels, establish and enhance the brand awareness, enrich the cultural connotation of community banks, establish a good brand image, form a good reputation, and then obtain more customer resources.

People are eager to get social identity and wish to own a status symbol that consistent with a relevant group. Community banks should set a We Chat public number and communicate with the customers freely in Two-way communication, also they should held a book club or invite the customers watch movies. Community banks can held lectures on financial knowledge with their own advantages, which involve the history of finance and the development of financial culture. We can also collect the relevant works of the community bank, reward the excellent works, and finally achieve the goal of promoting the culture of the community bank.

\section{F. Safety Experiential Strategy}

Safety experiential marketing emphasizes security. The key of the safety experience is the construction of user security. the formation of security is inseparable with personal experience and intuition. Security arises the accumulation of positive feedback in the process when the people contact with the outside world, so the security experience design should considered specific usage scenarios when a product or service used [6], it enable customers understand and grasp more about the safety products, safety knowledge and safety performance of the community banks.

Community banks should constantly innovate security products and service functions, put security in the first place, ensure that customers can safely use the various services of community banks. Community banks can provide remind function such as login, query and transaction services, and the user can master the use process at any time. At the same time, the customers can choose to remind project by himself, and this gives customers full control rights as far as possible and increases customers control; Community banks should automatically assess the security degree of bank customers' password, improve the security awareness of customers, and provide personalized security customization functions for customers by setting up private and other security technologies.

\section{Summary}

This paper studies the community banks' experiential marketing innovative strategy against the background of internet finance. It combed the theory of community banks' experiential marketing and other related theories, deeply analyzed the development status of community banks. At present, the Chinese community banks' creative ability is weak, its positioning is inaccurate, and its service homogeneity phenomenon is relatively serious. This study present experiential marketing innovative strategy from six aspects, such as the sensory experience, emotional experience, thinking experience, correlative experience and security experience according to the characteristics of experiential marketing. This paper hopes that Chinese community banks should truly implement the concept of "user first, customers experience is the King”, and pay more attention to the interaction with customers.

\section{REFERENCES}

[1] Wenxiang Yang. Under the background of the Internet financial banking innovative marketing strategy research[D]. Chengdu: Southwest Jiao Tong University, 2015, 6-8. (In Chinese)

[2] http://news.163.com/16/0606/02/BORGM3QE00014Q4P.html

[3] Yu Sun. Analysis of the marketing strategy of China's Community Banks[J].The modernization of the shopping mall. 2016, 55-56. (In Chinese)

[4] Shaozhu Tan. Research on Pricing Strategy and Method of Experiential marketing[J]. The price issue, 2016.07, 59-62. (In Chinese)

[5] Sugang Wang. Application of experiential marketing concept in enterprise marketing strategy-In IKEA [D]. Lanzhou: Lanzhou Jiao Tong University, 2015, 9-10 (In Chinese)

[6] Wei Wang, Su Zhou. The design of security experience in mobile payment[J]. Decoration, 2014.01, 95-96. (In Chinese) 